\title{
A physiological framework to explain genetic and environmental regulation of tillering in sorghum
}

\author{
Mohammad Mobashwer Alam ${ }^{1}$, Graeme L. Hammer ${ }^{1,2}$, Erik J. van Oosterom ${ }^{1,2}$, Alan W. Cruickshank ${ }^{3}$, Colleen H. \\ Hunt $^{3}$ and David R. Jordan ${ }^{4}$ \\ ${ }^{1}$ School of Agriculture and Food Sciences, The University of Queensland, Brisbane, Qld 4072, Australia; ${ }^{2}$ Queensland Alliance for Agriculture and Food Innovation, The University of \\ Queensland, Brisbane, Qld 4072, Australia; ${ }^{3}$ Department of Agriculture Forestry and Fisheries, Hermitage Research Facility, Warwick, Qld 4370, Australia; ${ }^{4}$ Queensland Alliance for \\ Agriculture and Food Innovation, Hermitage Research Station, The University of Queensland, Warwick, Qld 4370, Australia
}

Author for correspondence:

Erik J. van Oosterom

Tel: +61733469464

Email: erik.van.oosterom@uq.edu.au

Received: 4 November 2013

Accepted: 9 February 2014

New Phytologist (2014)

doi: 10.1111/nph.12767

Key words: carbon balance, environmental control, genetic diversity, hormones, organ size, sorghum, tillering.

\section{Summary}

- Tillering determines the plant size of sorghum (Sorghum bicolor) and an understanding of its regulation is important to match genotypes to prevalent growing conditions in target production environments. The aim of this study was to determine the physiological and environmental regulation of variability in tillering among sorghum genotypes, and to develop a framework for this regulation.

- Diverse sorghum genotypes were grown in three experiments with contrasting temperature, radiation and plant density to create variation in tillering. Data on phenology, tillering, and leaf and plant size were collected. A carbohydrate supply/demand (S/D) index that incorporated environmental and genotypic parameters was developed to represent the effects of assimilate availability on tillering. Genotypic differences in tillering not explained by this index were defined as propensity to tiller (PTT) and probably represented hormonal effects.

- Genotypic variation in tillering was associated with differences in leaf width, stem diameter and PTT. The S/D index captured most of the environmental effects on tillering and PTT most of the genotypic effects.

- A framework that captures genetic and environmental regulation of tillering through assimilate availability and PTT was developed, and provides a basis for the development of a model that connects genetic control of tillering to its phenotypic consequences.

\section{Introduction}

Tillers are a fundamental component of plant architecture that regulate yield (Kuraparthy et al., 2008) via direct effects on the number of panicles formed (Beall et al., 1991). Like the main shoot, they consist of a succession of phytomers that each contain a leaf blade, leaf sheath and stem internode. Tillers grow from axillary buds located in the axils of leaves, and their development involves the initiation of an axillary meristem, formation of the axillary bud and its subsequent outgrowth (Schmitz \& Theres, 2005). These three stages are regulated by the external environment, internal genetic background and their interactions (Beveridge et al., 2003; Shimizu-Sato et al., 2009; Whipple et al., 2011). Each axillary meristem has a window of opportunity for its outgrowth that is associated with the timing of expansion of subtending leaves (Lafarge et al., 2002; Kim et al., 2010b). Tillers also play an important role in biomass accumulation, as intercepted radiation is increased with the greater leaf area associated with tillering. Hence, high-tillering genotypes are better suited to favourable environments where they can maximize resource use. By contrast, in adverse environments, where water for transpiration is limited, low tillering is preferred to restrict plant size and thus increase post-anthesis water availability and grain yield (Hammer, 2006). Under water-limited conditions, excessive tillering can lead to high tiller abortion, poor grain set and small panicle size, thereby reducing grain yield (Kariali \& Mohapatra, 2007). To optimize grain yield, it is necessary to have a plant type with the appropriate productive tiller number and plant architecture for the prevailing conditions. Therefore, a clear understanding of the regulation of tillering in cereals is required to enable the matching of the genotypic capacity to produce tillers to the target population of environments in order to achieve high grain yield (Saracutu et al., 2010).

In conditions in which tillering is not affected by water or nitrogen stress, early growth of tillers depends on the availability of excess carbohydrate, which depends on the balance of supply (S) through the photosynthesis of expanded main shoot leaves and demand (D) for growth by the main shoot (Kirby et al., 1985; Lafarge, 2006). The carbohydrate S/D ratio has been used to relate tiller outgrowth to plant internal competition for resources between main stem and tillers in rice (Dingkuhn et al., 2006; Luquet et al., 2006), sorghum (Kim et al., 2010a,b) and wheat (Bos \& Neuteboom, 1998). The S/D ratio is a complex indicator of internal plant carbohydrate status, in which solar 
radiation and leaf area determine carbohydrate supply via photosynthesis, whereas temperature and leaf area growth determine carbohydrate demand associated with crop development (Hammer etal., 1993; Tardieu etal., 1999; Kim et al., 2010b). Assimilate demand by the main stem increases at high temperatures (Bos \& Neuteboom, 1998) in response to an increased rate of leaf area expansion, associated with more rapid leaf appearance (Lafarge et al., 1998). Assimilate supply per plant is reduced by low light interception, which can be a consequence of low incident radiation, short photoperiod, high plant density or defoliation (Bos \& Neuteboom, 1998; Gautier et al., 1999). In this context, increased leaf size in early development stages could reduce tillering, as large leaves increase early vigour of the main shoot and hence carbon demand. A negative correlation between tiller number and leaf size has been reported for sorghum (Kim etal., 2010a), perennial ryegrass (Lolium perenne) (Bahmani et al., 2000), pearl millet (Pennisetum glaucum) (van Oosterom et al., 2001), wheat (Triticum aestivum) (Rebetzke \& Richards, 1999) and rice (Oryza sativa) (Tivet etal., 2001). Although negative correlations between tillering and plant height have been observed in rice (Richards, 1988), the relationships between other leaf and plant size traits and tillering have not been fully elucidated.

Recent studies on tillering in a small number of sorghum genotypes have revealed that, although the S/D balance can explain part of the observed genotypic variation in maximum tiller number, the genotypes also differ in their propensity to tiller (PTT), which represents the endogenous genotypic differences in tillering that cannot be explained by differences in the S/D balance (Kim etal., 2010a). There is some understanding of the endogenous hormonal gene network that controls axillary branching in Arabidopsis, tomato, petunia and pea (Dun etal., 2006; Doust, 2007; McSteen, 2009; Yaish et al., 2010). Auxin from the shoot apical meristem inhibits the outgrowth of axillary tiller buds, whereas acropetal movement of cytokinin and strigolactones promotes and inhibits the growth of tiller buds, respectively (Beveridge, 2006; Gomez-Roldan etal., 2008; Ongaro etal., 2008; Umehara et al., 2008; McSteen, 2009). Some orthologous genes of these gene networks have also been found in rice and maize (Li et al., 2003; Takeda et al., 2003; Mao et al., 2007), and these have been found to control shoot branching through the alteration of different transcriptional and hormonal pathways (reviewed in Yaish et al., 2010). In addition, genes have been identified that regulate tillering by integrating extrinsic signals with endogenous cues, such as the gtl gene in maize, for which the expression is induced by the shade avoidance response (red : far red (R:FR) ratio of light) and depends on $t b 1$ (teosinte branched 1) activity (Whipple et al., 2011). Genotypic differences in PTT could thus represent differences in the hormones and intrinsic genotypic cues that regulate tillering.

Crop genotypic diversity and the associated growing environment contribute to phenotypic plasticity in tillering. However, the understanding of the physiological and genetic control of tillering in sorghum remains limited, and an improvement in this understanding could have significant implications for plant breeding. Hence, this study aimed: to explore the extent of genetic variability for tillering in sorghum; to determine the physiological and environmental regulation of the genetic variability in tillering; and to develop a framework to explain the environmental and genetic control of tillering. Our study hypothesized that the carbon S/D balance and the intrinsic tillering propensity could explain the physiological and environmental regulation of tillering variability across a wide range of sorghum germplasm.

\section{Materials and Methods}

\section{Genetic material}

A combination of 51-61 sorghum (Sorghum bicolor (L.) Moench) inbred lines and 39 hybrids were grown in three experiments. The inbred lines represented a diverse range of germplasm originating from North America, Australia, Africa and Asia (Table 1). They included parents of mapping populations, and male and female parents of hybrids.

\section{Experimental details}

One glasshouse (Expt 1) and two field (Expt 2 and Expt 3) experiments were carried out under contrasting temperature and radiation regimes to generate high and low-tillering conditions. Expt 1 was sown in September 2008 in a glasshouse at the University of Queensland, St Lucia, Qld, Australia $\left(27^{\circ} 28^{\prime} \mathrm{S}\right.$, $\left.153^{\circ} 1^{\prime} \mathrm{E}\right)$. Expt 2 and Expt 3 were sown in December 2008 and January 2010, respectively, in a field at Hermitage Research Facility, Warwick, Qld, Australia $\left(28^{\circ} 12^{\prime} \mathrm{S}, 152^{\circ} 5^{\prime} \mathrm{E}\right)$. In Expt 1, maximum and minimum air temperatures and total radiation were logged daily using a data logger (CR10; Campbell Scientific, Logan, UT, USA). For Expt 2 and Expt 3, weather data were recorded at a centrally located weather station. Average daily radiation, minimum and maximum temperatures, and thermal time were calculated for the first $45 \mathrm{~d}$ after emergence, coinciding with the period of tiller appearance. Thermal time was calculated from hourly data, using a broken linear relationship with cardinal temperatures of 11,30 and $42^{\circ} \mathrm{C}$ for the base, optimum and maximum temperatures, respectively (Hammer et al., 1993).

All three experiments were laid out as randomized complete block row and column designs with three replications. Genotypes were arranged using neighbour balance to allow for twodimensional spatial adjustments. Expt 1 included 51 inbred lines and 39 hybrids, and was laid out in six columns of 45 pots each to account for potential temperature gradients in the glasshouse. Pots of $30 \mathrm{~cm}$ in diameter were filled with pre-sterilized and prefertilized University of California soil mix (containing sand and peat). Four seeds were sown in each pot and, after emergence, plants were gradually thinned to one plant per pot by the fourleaf stage. The whorl of each axis in each plant was sprayed daily with $0.3 \% \mathrm{Ca}\left(\mathrm{NO}_{3}\right)_{2}$ after establishment to minimize symptoms of calcium deficiency. Three weeks after sowing, a $2 \%$ solution of liquid fertilizer aquasol $(23 \% \mathrm{~N}, 4 \% \mathrm{P}$ and $18 \% \mathrm{~K}$ in a composition of mono-ammonium phosphate, potassium nitrate, 
Table 1 Origin and characteristics of the 51 sorghum (Sorghum bicolor) inbred lines used in the experiments

\begin{tabular}{|c|c|c|}
\hline Genotype & Origin & Characteristics \\
\hline & Africa & \\
\hline Tx642(B35) & Ethiopia & $\begin{array}{l}\text { Partially converted IS 12555, highly } \\
\text { stay-green }\end{array}$ \\
\hline IS 8525 & Ethiopia & $\begin{array}{l}\text { Parent of mapping population for } \\
\text { ergot resistance }\end{array}$ \\
\hline SC111-14E & Ethiopia & $\begin{array}{l}\text { Fully converted zera zera landrace } \\
\text { Gambela No } 6\end{array}$ \\
\hline SC103-14E & Ethiopia & $\begin{array}{l}\text { Conversion of a breeding line from } \\
\text { South Africa, guinea-caudatum }\end{array}$ \\
\hline SC108C & Ethiopia & $\begin{array}{l}\text { Fully converted bicolor-kafir landrace } \\
\text { Gambela No } 1\end{array}$ \\
\hline SC170-6-8 & Ethiopia & $\begin{array}{l}\text { High yielding, partly converted version } \\
\text { of IS12661 a caudatum line ex } \\
\text { Ethiopia }\end{array}$ \\
\hline SC23 & Ethiopia & A durra genotype \\
\hline SC35C & Ethiopia & $\begin{array}{l}\text { Fully converted durra landrace IS } \\
12555, \text { source of stay-green }\end{array}$ \\
\hline SC999 & Ethiopia & $\begin{array}{l}\text { Partially converted durra-bicolor } \\
\text { landrace IS } 11080\end{array}$ \\
\hline ISCV400 & Mali & $\begin{array}{l}\text { Bred by ICRISAT as a food sorghum in } \\
\text { Mali, 2-dwarf, white grain }\end{array}$ \\
\hline Malisor 84-7 & Mali & $\begin{array}{l}\text { Advanced line from Mali, described as } \\
\text { kafir-caudatum }\end{array}$ \\
\hline SC1075-8 & Nigeria & $\begin{array}{l}\text { Partial conversion of a landrace from } \\
\text { Nigeria }\end{array}$ \\
\hline MP531 & Southern Africa & $\begin{array}{l}\text { Breeding line, 2-dwarf, obtained via } \\
\text { TAMU }\end{array}$ \\
\hline SC56-14E & Sudan & $\begin{array}{l}\text { Source of stay-green drought } \\
\text { resistance, fully converted caudatum } \\
\text { landrace }\end{array}$ \\
\hline SC62C & Sudan & $\begin{array}{l}\text { A high-tillering genotype, fully } \\
\text { converted caudatum-bicolor landrace }\end{array}$ \\
\hline \multirow[t]{2}{*}{ SC636-6 } & Uganda & $\begin{array}{l}\text { Partial conversion of a caudatum } \\
\text { landrace }\end{array}$ \\
\hline & America & \\
\hline Dorado & El Salvador & $\begin{array}{l}\text { Moderately fungal disease resistant, } \\
\text { hard endosperm }\end{array}$ \\
\hline Karper 669 & USA & $\begin{array}{l}\text { Diverse yellow endosperm germplasm } \\
\text { line }\end{array}$ \\
\hline KS115 & USA & Large seed \\
\hline MLT135 & USA & $\begin{array}{l}\text { Elite moderately senescent parent line } \\
\text { ex TAMU breeding programme }\end{array}$ \\
\hline R9188 & USA & $\begin{array}{l}\text { Partially converted derivatives of sweet } \\
\text { sorghum Rio }\end{array}$ \\
\hline R9733 & USA & $\begin{array}{l}\text { Breeding line from Texas A\&M } \\
\text { University breeding programme }\end{array}$ \\
\hline Rio & USA & Sweet sorghum \\
\hline TAM422 & USA & $\begin{array}{l}\text { Early hybrid parent lacking in stay- } \\
\text { green drought resistance }\end{array}$ \\
\hline Tx2536 & USA & $\begin{array}{l}\text { Early hybrid parent lacking in stay- } \\
\text { green drought resistance }\end{array}$ \\
\hline Tx2737 & USA & $\begin{array}{l}\text { High-yielding, yellow endosperm, } \\
\text { widely used as parent commercially in } \\
\text { the USA }\end{array}$ \\
\hline T×2895 & USA & Widely used commercially in the USA \\
\hline Tx430 & USA & $\begin{array}{l}\text { Yellow endosperm, widely used as } \\
\text { parent commercially in the USA }\end{array}$ \\
\hline TX623 & USA & $\begin{array}{l}\text { An elite US female pedigree BT×3197/ } \\
\text { SC170-6-4-4 }\end{array}$ \\
\hline
\end{tabular}

Table 1 (Continued)

\begin{tabular}{|c|c|c|}
\hline Genotype & Origin & Characteristics \\
\hline \multirow[t]{2}{*}{ TX7000 } & USA & $\begin{array}{l}\text { Early hybrid parent lacking in stay- } \\
\text { green drought resistance }\end{array}$ \\
\hline & Asia & \\
\hline $\mathrm{Ai} 4$ & China & $\begin{array}{l}\text { 2-dwarf, photoperiod-insensitive, } \\
\text { possible cold tolerance }\end{array}$ \\
\hline LR2490-3 & China & $\begin{array}{l}\text { Breeding line, 2-dwarf, classified as } \\
\text { zera zera }\end{array}$ \\
\hline LR9198 & China & $\begin{array}{l}\text { Breeding line, 2-dwarf, male of a good } \\
\text { hybrid in China }\end{array}$ \\
\hline ICSV745 & India & Parent of mapping population \\
\hline M35-1 & India & Drought resistant \\
\hline RS29 & $\begin{array}{l}\text { India } \\
\text { Australia }\end{array}$ & Drought resistant \\
\hline B923296 & Australia & $\begin{array}{l}\text { Elite stay-green parent ex QPIF } \\
\text { breeding programme }\end{array}$ \\
\hline QL12 & Australia & $\begin{array}{l}\text { Source of stay-green drought } \\
\text { resistance }\end{array}$ \\
\hline QL33 & Australia & $\begin{array}{l}\text { Elite moderately senescent parent line } \\
\text { ex QPIF breeding programme }\end{array}$ \\
\hline QL36 & Australia & $\begin{array}{l}\text { Elite moderately senescent parent line } \\
\text { ex QPIF breeding programme }\end{array}$ \\
\hline R890562 & Australia & $\begin{array}{l}\text { Elite moderately senescent parent line } \\
\text { ex QPIF breeding programme }\end{array}$ \\
\hline R931945-2-2 & Australia & $\begin{array}{l}\text { Elite stay-green parent ex QPIF } \\
\text { breeding me }\end{array}$ \\
\hline R9403463-2-1 & Australia & $\begin{array}{l}\text { Elite moderately senescent parent line } \\
\text { ex QPIF breeding programme }\end{array}$ \\
\hline R993396 & Australia & $\begin{array}{l}\text { Elite moderately senescent parent line } \\
\text { ex QPIF breeding programme }\end{array}$ \\
\hline R999003 & Australia & $\begin{array}{l}\text { Selected from an interspecific cross } \\
\text { between S. arundinaceum (African } \\
\text { wild-type high tillering) and } \\
\text { R931945-2-2 (low tillering) }\end{array}$ \\
\hline R999017 & Australia & As for R990003 \\
\hline R999066 & Australia & As for R990003 \\
\hline R999081 & Australia & As for R990003 \\
\hline R999110 & Australia & As for R990003 \\
\hline R999197 & Australia & As for R990003 \\
\hline R999218 & Australia & As for R990003 \\
\hline
\end{tabular}

urea, potassium chloride, zinc sulfate, copper sulfate, sodium molybdate, manganese sulfate, sodium ferric EDTA and sodium borate) was added in two consecutive weeks to provide additional nitrogen and to ensure that nutrients were nonlimiting. Watering was performed regularly and no drought stress occurred. The experiment was terminated after the completion of flowering.

The field experiments (Expts 2 and 3) included the 90 genotypes of Expt 1 and an additional 10 Near Isogenic Lines (NILs). Plots were distributed in 30 ranges of 10 rows and consisted of one row of $4.75 \mathrm{~m}$ in length each. The sites were fertilized and cultivated before planting. The experiments were machine planted with a row spacing of $75 \mathrm{~cm}$ and thinned at the threeleaf stage to a plant-to-plant spacing of $>70 \mathrm{~cm}$ (Expt 2) or $45-50 \mathrm{~cm}$ (Expt 3). Weeding was performed as and when necessary. Experiments were rain-fed and terminated after the completion of flowering. 
Table 2 Abbreviations of plant parameters used in this study

\begin{tabular}{|c|c|}
\hline Abbreviation & Trait \\
\hline DTA & Days to anthesis (d) \\
\hline ID & Internode diameter $(\mathrm{cm})$ \\
\hline IL & Inflorescence length $(\mathrm{cm})$ \\
\hline LA5 & Area of Leaf $5\left(\mathrm{~cm}^{2}\right)$ \\
\hline LL & Length $(\mathrm{cm})$ of designated leaf number \\
\hline LLIR & Leaf length increase rate from 5 th to 9 th leaf ( $\mathrm{cm}$ per leaf) \\
\hline LW & Width $(\mathrm{cm})$ of designated leaf number \\
\hline LWIR & Leaf width increase rate from 5 th to 9 th leaf ( $\mathrm{cm}$ per leaf) \\
\hline N_BT & Basal tiller number \\
\hline N_FT & Fertile tiller number \\
\hline N_TT & Total tiller number \\
\hline PH_BFL & Plant height from base to flag leaf $(\mathrm{cm})$ \\
\hline $\mathrm{PH} \_\mathrm{BI}$ & Plant height from base to joint of inflorescence $(\mathrm{cm})$ \\
\hline Phyl & Phyllochron ( ${ }^{\circ} \mathrm{Cd}$ per leaf) \\
\hline PTT & Propensity to tiller \\
\hline$S / D$ & Supply/demand index \\
\hline TLN & Total leaf number \\
\hline TPH & Plant height from base to inflorescence apex $(\mathrm{cm})$ \\
\hline
\end{tabular}

\section{Observations}

Data on leaf and plant size, leaf appearance and tiller number were recorded on one plant per genotype in each replication in each experiment. The number of visible and fully expanded leaves on the main shoot and the number of emerged tillers were recorded three times a week. A leaf was considered to be visible if its tip was visible inside the whorl, and fully expanded if its ligule was visible above the ligule of the previous leaf. Abbreviations of measurements taken on different plant parameters are shown in Table 2. Total leaf number (TLN) at anthesis was the number of fully expanded leaves produced on the main shoot. Leaf appearance rate (LAR) was calculated as the slope of the regression of fully expanded leaf number on cumulative thermal time, excluding the last few leaves that appear at a faster rate. Leaf size was represented by the final leaf length (LL) and maximum leaf width (LW) of main shoot leaves 5, 7 and 9. Leaf area (LA) was obtained by multiplying the length and width by a shape coefficient of 0.69 (Kim et al., 2010b). The internode diameter (ID) was measured using digital slide callipers on the narrowest region of the first internode above the basal root zone, after removal of the leaf sheath. Plant height was measured from the base of the plant to the flag leaf (PH_BFL) or the base of the inflorescence (PH_BI). Adding the measurement of the inflorescence length (IL) yielded the total plant height (TPH). Days to anthesis (DTA) was measured as the number of days after emergence to the first date of pollen shed. Tillers were named after the main shoot leaf axil from which they appeared; for example, T3 appeared from the axil of Leaf 3. Basal tiller number (N_BT) included only primary tillers, whereas total tiller number (N_TT) included primary, secondary and tertiary tillers. Fertile tiller number (N_FT) included all tillers that produced a panicle.

A plant carbohydrate S/D index was estimated to quantify environmental and genotypic effects on tillering using a modified version of the index presented by Kim et al. (2010a):
S/D index $=\frac{\mathrm{RAD}_{\mathrm{LED} 5} \times \mathrm{LA}_{\mathrm{L} 5} \times \text { phyllochron }(\text { ligule to ligule })}{\operatorname{LLIR}(5-9) \times \operatorname{LWIR}(5-9)}$

Eqn 1

where $\mathrm{RAD}_{\mathrm{LED} 5}$ is the average incident global radiation per unit thermal time $\left(\mathrm{MJ} \mathrm{m}^{-2 \circ} \mathrm{Cd}^{-1}\right)$ during the period of expansion of main shoot leaf 5 (LED5, $\left.{ }^{\circ} \mathrm{Cd}\right), \mathrm{LA}_{\mathrm{L} 5}$ is the fully expanded area of L5, which was expanding at the start of tillering, and LLIR (5-9) and LWIR(5-9) are the linear rates of increase in the maximum leaf length and maximum leaf width, respectively, for successive leaves between L5 and L9. The duration of expansion of main shoot leaf 5 (LED5) was calculated as the thermal time between the appearance of its tip and ligule. The phyllochron (Phyl, ${ }^{\circ} \mathrm{Cd}$ per leaf), which is the average thermal time for appearance per leaf from Leaf 5 to Leaf 9, was used in this study in place of LED5 which was employed by Kim et al. (2010a). The phyllochron does not require observations on leaf tip appearance and, because it is the average appearance across five leaves, its value is likely to be more robust than LED5 used by Kim et al. (2010a). The numerator of Eqn 1 is considered as an index of carbohydrate supply to the plant during tillering and the denominator as an index of carbohydrate demand by the main shoot. Hence, a high S/D index would favour tillering. The S/D index was calculated for each genotype in each experiment, using the average of the S/D indices calculated for individual replications.

The PTT of each genotype was calculated from the relationship of N_TT to the S/D index. Initially, a linear regression of N_TT on the S/D index was fitted across data from all genotypes and experiments (excluding SC62C germplasm, which produced secondary tillers). The average PTT was derived as the $y$-intercept of the regression (i.e. N_TT when the S/D index is zero). The vertical deviation of each point from the regression line was used to adjust the average PTT to obtain the PTT estimate for each genotype in each experiment. A high value for PTT indicated an above average tiller number for a given S/D index. The average PTT across the three experiments for each genotype was taken as the PTT for that genotype.

\section{Data analyses}

Statistical analyses were performed using a linear mixed model for each trait. Variance estimates of genetic parameters and genotypic values of each trait were derived from a REML mixed model allowing for spatial variation within each experiment (Gilmour et al., 1997). The general form of the mixed model is:

$\mathbf{y}=\mathbf{X} \tau+\mathbf{Z}_{g} \mathbf{u}_{g}+\mathbf{Z}_{0} \mathbf{u}_{0}+\mathbf{e}$

Eqn 2

where the vector $\mathbf{y}$ represents the observed values of a trait with length $n, n=i \times j \times k$ with $i$ experiments $(i=3), j$ genotypes $(j=100)$ and $k$ replicates $(k=3) . \mathbf{X}$ is the design matrix for the fixed effects and $\tau$ is the vector of fixed effects containing a mean trait value for each experiment. $\mathbf{Z}_{\mathrm{g}}$ is the design matrix for the random genetic effects and $\mathbf{u}_{\mathrm{g}}$ represents the $i \times j$ random effects for genotypes in environments. $\mathbf{Z}_{\mathrm{o}}$ is the design matrix for the peripheral random effects and $\mathbf{u}_{\mathrm{o}}$ represents the random effects 
for the peripheral terms. The peripheral terms include replication and effects caused by rows and columns for each environment, and a within-plot effect for Expt 1.

The genotype effects $\mathbf{u}_{\mathrm{g}}$ have a normal distribution with zero mean and variance given by $\mathbf{I} \otimes \mathbf{G}$, where $\mathbf{I}$ is a $(j \times j)$ matrix containing ' 1 ' on the diagonal and ' 0 ' elsewhere and $\mathbf{G}$ is a $(i \times i)$ matrix that controls the structure of the genotype by environment interaction. In across-experiment analyses, correlated error terms in the variance-covariance matrix structure $\mathbf{G}$ are required to allow for the heterogeneity of error variance across environments (Borràs et al., 2009). G is either a diagonal matrix with genetic variances on the diagonal and ' 0 ' on the off-diagonals, analogous to a single-site analysis, or a correlation matrix containing genetic variances on the diagonal and between site co-variances on the off-diagonals. Genotype $\times$ environment $(\mathrm{G} \times \mathrm{E})$ interaction is assessed by examination of the correlation $\mathbf{G}$ matrix.

An initial assessment of the significance of $\mathrm{G} \times \mathrm{E}$ interactions in a mixed model of the form of Eqn 2 was modified to allow fixed effects for genotypes, experiments and their interaction with random effects as before, including all the extraneous errors $\left(\mathbf{u}_{0}\right)$. This model was used to provide a statistical test in the form of a Wald test to test for a significant $\mathrm{G} \times \mathrm{E}$ interaction. Predicted phenotypic values for each genotype in each experiment were estimated from best linear unbiased predictors (BLUPs) from the random effects model. Both the fixed and random versions of the models were fitted using REML linear mixed procedures in Genstat 13.0 (Payne et al., 2009). Estimates of variance components for genetic variance and error variance $\left(\sigma_{\mathrm{g}}^{2}\right.$ and $\left.\sigma_{\mathrm{e}}^{2}\right)$ were used for the estimation of broad-sense heritability and coefficients of variation within each site.

To indicate the magnitude of variability, coefficients of variation were estimated using:

Phenotypic coefficient of variation, $\mathrm{PCV}=\frac{\sqrt{ } \sigma_{p h}^{2}}{\bar{X}} \times 100$ Eqn 3

Genotypic coefficient of variation, GCV $=\frac{\sqrt{ } \sigma_{g}^{2}}{\bar{X}} \times 100$

Eqn 4

where $\sigma_{p h}^{2}$ is the phenotypic variance, $\sigma_{g}^{2}$ is the genotypic variance and $\bar{X}$ is the grand mean. Although GCV indicates the extent of genetic variation of a trait, this is insufficient to describe the perpetuation of genes from one generation to the next (Johnson et al., 1963). Therefore, broad-sense heritabilities were estimated to indicate the effectiveness of selection of genotypes based on phenotypic performance. As a result of a mixed model containing random spatial effects, the general formula for broadsense heritability does not apply; instead, an approximation of broad-sense heritability can be calculated for each experiment using the formula of Cullis et al. (2006):

Broad-sense heritability $H=1-\frac{a v S E D^{2}}{2 \sigma_{g}^{2}}$

Eqn 5 where $a v S E D^{2}$ is the average pairwise prediction error and $\sigma_{\mathrm{g}}^{2}$ is the within-site genetic variance components resulting from the mixed model analysis.

The estimation of genetic correlation among traits and principal component analyses were performed in Genstat 13.0 (Payne et al., 2009) using BLUPs. Biplots were used to approximate the genetic correlation between two variables from the cosine angle formed by their vectors, only when the first two principal components represented most of the variation. When the two principal components failed to explain most of the variation, genetic correlations were derived from direct estimation (Borràs et al., 2009). As the 10 NILs were not included in all three experiments, standardized values of these entries were excluded from results other than variance analyses.

\section{Results}

\section{Environmental and genotypic variation in tillering}

Average radiation in the glasshouse experiment (Expt 1) was 2.5-3-fold lower than that in the field experiments (Expt 2 and Expt 3), but the average temperature was $3.5-4^{\circ} \mathrm{C}$ higher (Table 3). In the field experiments, Expt 2 received less rainfall than Expt 3, and this was combined with higher average daily radiation and maximum temperature. The genotypic means for total tiller number, estimated from single-site analyses as best linear unbiased estimators (BLUEs), were consistently lower in Expt 1 than in Expts 2 and 3 (Fig. 1; Supporting Information Tables $S 1, S 2)$, indicating the negative effects of low radiation, high temperature and high plant density on tillering in the glasshouse experiment.

The variation in total and fertile tiller number was narrower for hybrids than for inbred lines (Tables 4, 5) and, on average, the CV for N_FT and N_TT for inbred lines was nearly double that for hybrids. In all three experiments, SC62C produced the highest tiller number among the inbred lines and in hybrid form, as it was the only genotype that produced secondary and tertiary tillers. In inbred lines, total tiller number varied from 0.0 to 9.5 (Expt 1), 0.6 to 15.6 (Expt 2) and 0.9 to 12.7 (Expt 3 ), whereas, for fertile tillers, it ranged from 0 to 5.6 (Expt 1), 0.3 to 13.7 (Expt 2) and 0.7 to 11.9 (Expt 3). Variance components differed significantly within and across experiments (Table 6).

The initial assessment using fixed genotype and experiment effects gave a highly significant $\mathrm{G} \times \mathrm{E}$ interaction for total tiller number (Table 6, Fig. 1). However, the statistically more accurate model for these data was the random effects genotype by experiment with a common correlation model, where each experiment has a different genetic variance. The correlation between experiments was determined to be 0.917 , indicating a high agreement on genetic ranking between the experiments. The estimate of broad-sense heritability of this trait was high within all experiments (Table 6). The higher broad-sense heritability in Expt 2 compared with the other two experiments was associated with the increased $\sigma_{\mathrm{g}}^{2}$ in that experiment. 
Table 3 Attributes and environmental conditions for the three experiments

\begin{tabular}{|c|c|c|c|}
\hline Environmental parameters & Expt 1 & Expt 2 & Expt 3 \\
\hline Experimental sites & St Lucia, glasshouse & Warwick, field & Warwick, field \\
\hline Sowing date & 11 September 2008 & 17 December 2008 & 3 February 2010 \\
\hline Spacing & $30 \mathrm{~cm} \times 30 \mathrm{~cm}$ & $75 \mathrm{~cm} \times 75 \mathrm{~cm}$ & $50 \mathrm{~cm} \times 75 \mathrm{~cm}$ \\
\hline Average radiation ${ }^{a}\left(M^{\prime} m^{-2} d^{-1}\right)$ & 7.8 & 24.9 & 18.3 \\
\hline Average daily minimum temperature ${ }^{\mathrm{a}}\left({ }^{\circ} \mathrm{C}\right)$ & 20.2 & 16.0 & 16.7 \\
\hline Average daily maximum temperature ${ }^{\mathrm{a}}\left({ }^{\circ} \mathrm{C}\right)$ & 31.9 & 28.7 & 26.0 \\
\hline Thermal time $\left({ }^{\circ} \mathrm{Cd}^{-1}\right)$ & 13.1 & 10.6 & 10.0 \\
\hline Total rainfall ${ }^{\mathrm{b}}(\mathrm{mm})$ & Irrigated & 40.9 & 160.3 \\
\hline
\end{tabular}

${ }^{\mathrm{a}}$ For the period up to final primary tiller appearance.

${ }^{\mathrm{b}}$ For the period until anthesis.

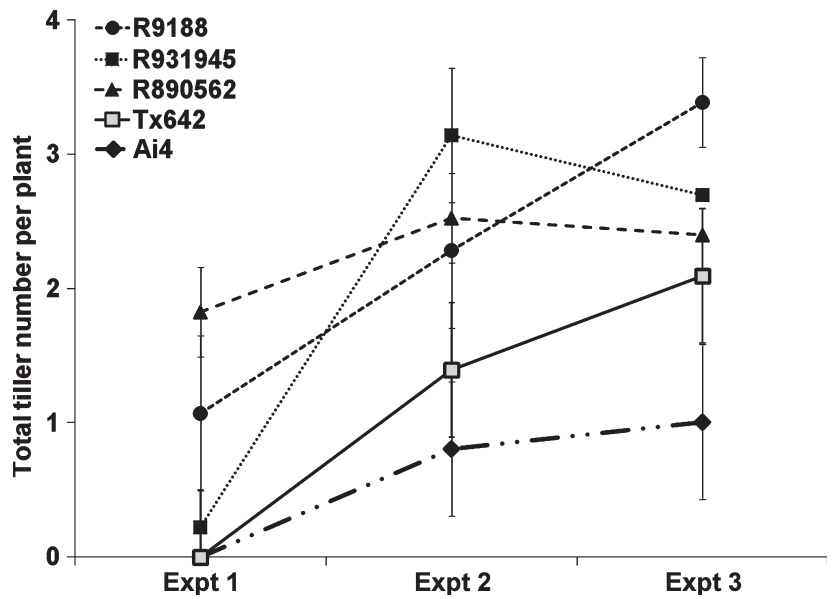

Fig. 1 Total tiller number per plant for five selected sorghum (Sorghum bicolor) genotypes in the three experiments conducted in this study. Error bars show \pm 1 SE.

The PCV was consistently greater than the GCV (Table 6), indicating that the observed variation in total tiller number was caused by both genotypic and environmental effects. Variation in GCV and PCV across experiments indicated that genotypic variation in tillering was environment dependent. The combination of high GCV and high broad-sense heritability indicates high genetic regulation of this trait.

Although genetic correlations for total tiller number between pairs of environments ranged from 0.92 (hybrids) to 0.95 (inbred lines in Expt 2 vs Expt 3, Table S3), the patterns of response across the three experiments indicated the existence of some $\mathrm{G} \times \mathrm{E}$ interactions (Fig. 1). In particular, genotypes with different tiller numbers in the high-tillering conditions of Expt 2 and Expt 3 had similar tiller numbers in Expt 1, where many genotypes produced virtually no tillers in its low-tillering conditions. In general, $\mathrm{G} \times \mathrm{E}$ interactions were of a non-crossover type, although some crossover-type interactions occurred for selected $\mathrm{G} \times \mathrm{E}$ combinations (Fig. 1).

\section{Relationship of morphological traits with tillering}

Tiller number was only weakly negatively correlated with phenology. Early genotypes that produced few leaves tended to have greater tiller numbers than later genotypes that produced more leaves (Table 7). This weak negative correlation was consistent with the right angle of the respective vectors in the biplot (Fig. 2). Although genetic correlations were stronger (Table 8), it was unlikely that genotypic differences in phenology had a major effect on differences in tillering.

Tiller number was significantly negatively correlated with ID and LWIR in both inbred lines and hybrids (Table 7), consistent with the wide angle between the directional vectors in the covariate-effect biplots (Fig. 2). However, the association between ID and LWIR was weak (Table 7, Fig. 2). The genetic correlation for LWIR and, in particular, ID between pairs of experiments was as high as for tillering itself (Table S3), indicating a robustness of these traits across experiments. LLIR, however, showed no association with tiller number, which may have been a result of the low broad-sense heritability (Table S3) and limited genotypic differences (short arrow in Fig. 2). The correlation of tillering with leaf size (LWIR) and ID suggests that tillering may at least partly be associated with the size of the main shoot, and hence potentially with the S/D index.

\section{S/D index and PTT}

The S/D index explained $56 \%$ of the variation in total tiller number across genotypes and experiments (Fig. 3). This high $R^{2}$ was associated, to a large extent, with environmental effects on tillering across experiments, as the glasshouse experiment (Expt 1) combined a low $S / D$ index with low tiller number. However, the association between $S / D$ index and tiller number was weak (Table 7) and the genetic correlation non-significant (Table 8). Nonetheless, in accordance with Eqn 1, the genetic correlation of S/D with LWIR was significantly negative and that with the area of Leaf 5 (LA5) significantly positive (Table 8 ). By contrast, the PTT explained $71 \%$ of the genotypic variation in tillering (Fig. 4). Like tiller number, the genotypic correlations of PTT with LWIR and ID were significantly negative. Genetic correlations between pairs of experiments and the broad-sense heritability were low for the S/D index, but high for PTT (Table S3). Because the genetic correlation between PTT and tiller number was highly significant (Table 8), the results suggest that environmental differences in tillering were predominantly associated with differences in the S/D index, whereas genotypic differences in tillering were rather associated with intrinsic genotypic differences in an ability to produce tillers. 
Table 4 Minimum (MIN), maximum (MAX), mean and coefficient of variation (CV) of observed data for all traits across the three experiments for sorghum (Sorghum bicolor) inbred lines

\begin{tabular}{|c|c|c|c|c|c|c|c|c|c|c|c|c|}
\hline \multirow[b]{2}{*}{ Traits $^{\mathrm{a}}$} & \multicolumn{4}{|l|}{ Expt 1} & \multicolumn{4}{|l|}{ Expt 2} & \multicolumn{4}{|l|}{ Expt 3} \\
\hline & MIN & MAX & Mean & $\mathrm{CV}$ & MIN & MAX & Mean & CV & MIN & MAX & Mean & $C V$ \\
\hline TLN & 10.4 & 17.7 & 14.8 & 0.11 & 14.1 & 22.2 & 17.8 & 0.08 & 12.5 & 18.7 & 16.3 & 0.07 \\
\hline TPH & 66.0 & 293.2 & 123.3 & 0.31 & 68.7 & 249.4 & 102.2 & 0.27 & 67.0 & 252.8 & 110.4 & 0.29 \\
\hline ID & 9.8 & 21.4 & 16.1 & 0.13 & 12.9 & 27.0 & 20.1 & 0.11 & 12.4 & 24.3 & 18.7 & 0.12 \\
\hline LA5 & 14.5 & 49.7 & 31.8 & 0.27 & 9.7 & 29.3 & 19.5 & 0.24 & 20.4 & 52.7 & 33.5 & 0.25 \\
\hline Phyl & 46.5 & 60.0 & 50.7 & 0.06 & 33.7 & 43.1 & 37.5 & 0.06 & 33.5 & 44.1 & 38.4 & 0.07 \\
\hline LLIR & 6.22 & 11.02 & 9.05 & 0.12 & 4.27 & 8.76 & 6.07 & 0.13 & 5.11 & 8.93 & 6.68 & 0.12 \\
\hline LWIR & 0.68 & 1.43 & 1.08 & 0.13 & 0.66 & 1.34 & 0.93 & 0.15 & 0.74 & 1.48 & 1.1 & 0.13 \\
\hline$S / D$ & 40.9 & 258.2 & 128.6 & 0.37 & 109.7 & 588.9 & 308.2 & 0.30 & 167.4 & 549.2 & 315.6 & 0.24 \\
\hline DTA & 52.8 & 72.8 & 64.7 & 0.07 & 55.9 & 76.1 & 66.7 & 0.06 & 60.5 & 76.3 & 69.0 & 0.06 \\
\hline N_FT & 0 & 5.57 & 0.14 & 5.71 & 0.33 & 13.66 & 2.52 & 0.71 & 0.7 & 11.89 & 2.25 & 0.69 \\
\hline N_TT & 0 & 9.46 & 1.11 & 1.27 & 0.63 & 15.6 & 2.87 & 0.72 & 0.85 & 12.68 & 2.92 & 0.56 \\
\hline PTT & -1.11 & 3.86 & 0.43 & 2.49 & -0.3 & 5.18 & 1.00 & 0.94 & -0.51 & 5.09 & 1.14 & 0.85 \\
\hline
\end{tabular}

${ }^{\mathrm{a}}$ For abbreviations of traits, see Table 2.

Table 5 Minimum (MIN), maximum (MAX), mean and coefficient of variation (CV) of observed data for all traits across the three experiments for sorghum (Sorghum bicolor) hybrids

\begin{tabular}{|c|c|c|c|c|c|c|c|c|c|c|c|c|}
\hline \multirow[b]{2}{*}{ Traits $^{\mathrm{a}}$} & \multicolumn{4}{|l|}{ Expt 1} & \multicolumn{4}{|l|}{ Expt 2} & \multicolumn{4}{|l|}{ Expt 3} \\
\hline & MIN & MAX & Mean & $C V$ & MIN & MAX & Mean & $C V$ & MIN & MAX & Mean & $C V$ \\
\hline TLN & 11.0 & 17.8 & 14.1 & 0.11 & 14.3 & 23.8 & 17.1 & 0.09 & 13.1 & 19.0 & 15.7 & 0.08 \\
\hline TPH & 111.5 & 158.8 & 133.3 & 0.08 & 91.6 & 123.9 & 107.8 & 0.07 & 99.5 & 143.7 & 121.7 & 0.09 \\
\hline ID & 12.5 & 21.9 & 17.1 & 0.11 & 15.6 & 26.8 & 21.0 & 0.09 & 15.7 & 23.5 & 19.9 & 0.08 \\
\hline LA5 & 18.8 & 53.8 & 35.9 & 0.21 & 14.0 & 36.7 & 21.6 & 0.21 & 26.0 & 51.1 & 36.6 & 0.16 \\
\hline Phyl & 45.5 & 55.8 & 49.7 & 0.04 & 32.6 & 40.2 & 36.4 & 0.05 & 33.3 & 41.2 & 37.5 & 0.04 \\
\hline LLIR & 6.22 & 10.39 & 8.96 & 0.10 & 4.74 & 7.6 & 6.31 & 0.08 & 4.85 & 7.7 & 6.83 & 0.08 \\
\hline LWIR & 0.82 & 1.41 & 1.16 & 0.10 & 0.75 & 1.26 & 1.03 & 0.10 & 0.92 & 1.44 & 1.17 & 0.09 \\
\hline$S / D$ & 41.4 & 221.6 & 120.4 & 0.32 & 182.9 & 391.4 & 267.7 & 0.17 & 221.8 & 430.8 & 302.3 & 0.16 \\
\hline DTA & 53.0 & 68.6 & 60.8 & 0.06 & 55.7 & 75.3 & 62.3 & 0.06 & 59.9 & 72.0 & 64.8 & 0.04 \\
\hline N_FT & 0 & 2.16 & 0.2 & 2.80 & 1.68 & 5.4 & 2.65 & 0.44 & 1.71 & 4.81 & 2.51 & 0.29 \\
\hline N_TT & 0.05 & 4.01 & 1.07 & 0.90 & 1.87 & 7.3 & 2.87 & 0.45 & 1.87 & 6.68 & 3.12 & 0.32 \\
\hline PTT & -0.4 & 2.8 & 0.55 & 1.44 & -0.12 & 3.65 & 1.3 & 0.61 & 0 & 3.33 & 1.45 & 0.48 \\
\hline
\end{tabular}

${ }^{\mathrm{a}}$ For abbreviations of traits, see Table 2 .

\section{Discussion}

This study examined the variability of tillering in a diverse range of germplasm to identify physiological determinants of genotypic differences in tillering. Small leaves and narrow stems were associated with a high tiller number, indicating a role of the carbon $\mathrm{S} / \mathrm{D}$ index in tillering. This index explained most of the environmental effects on tillering, allowing subsequent identification of causes for genotypic differences in tillering across environments. The S/D index explained some of the genotypic differences in tillering, whereas the PTT, which represents effects that are independent of the $S / D$ index and are probably associated with hormones, explained a major part of these genotypic differences. The results validate the framework developed by Kim et al. (2010a,b) across a wide range of sorghum germplasm, and allow the production of a generic tillering framework that provides a basis for the development of a model for the genetic control of tillering.

\section{S/D index captured environmental effects on tillering}

The S/D index captured most of the environmental effects on tillering and explained $56 \%$ of the variation in the total tiller number across genotypes and experiments (Fig. 3). Each tiller has a window of opportunity for its appearance equivalent to one phyllochron (Kim et al., 2010b). The duration of this period is determined by temperature, but whether this tiller actually grows is partly determined by assimilate availability, which is determined by the radiation intercepted by the plant (Hammer etal., 2010). The low tiller number in Expt 1 relative to Expt 2 and Expt 3 (Fig. 1) was consistent with this theory and with the results of Kim etal. (2010a,b). Hence, radiation per unit thermal time during

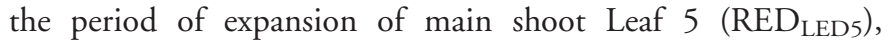
which is part of the calculation of the S/D index (Eqn 1), provides a powerful means to capture environmental effects on tillering. 
Small main shoot organ size is associated with increased tillering

The importance of the carbon status of the crop to tillering was highlighted by the significant association between tillering and LWIR (Tables 7, 8). Small leaves reduce carbohydrate demand by the main shoot and could thus increase carbohydrate availability for tillering (Eqn 1). A negative association between leaf size and tillering has been observed for rice (Tivet et al., 2001), wheat (Rebetzke et al., 2004), sorghum (Lafarge et al., 2002; van Oosterom etal., 2011) and pearl millet (van Oosterom et al., 2001), but also across species, as the decline in leaf width from maize to sorghum to pearl millet is associated with an increase

Table 6 Analyses of variance and estimates of genetic parameters for total tiller number in sorghum (Sorghum bicolor) estimated in the three experiments

\begin{tabular}{lrccl}
\hline & df & Sum of squares & Wald statistic & $\operatorname{Pr}\left(\chi^{2}\right)$ \\
\hline (Intercept) & 1 & 2378.8 & 2378.8 & $<2.2 \mathrm{e}-16^{* * *}$ \\
Site & 2 & 75.52 & 75.52 & $<2.2 \mathrm{e}-16^{* * *}$ \\
Genotype & 99 & 2965.87 & 2965.87 & $<2.2 \mathrm{e}-16^{* * *}$ \\
Site : genotype & 187 & 512 & 512 & $<2.2 \mathrm{e}-16 * * *$ \\
Residual (MS) & & 1 & & \\
\hline
\end{tabular}

\section{Genetic}

parameters

Expt $1 \quad$ Expt $2 \quad$ Expt 3

\begin{tabular}{llll}
\hline Mean & 1.10 & 2.79 & 3.03 \\
$\sigma_{g}^{2}(\mathrm{SE})$ & $1.15(0.19)$ & $3.13(0.48)$ & $1.71(0.27)$ \\
$\sigma_{e}^{2}(\mathrm{SE})$ & $0.34(0.05)$ & $0.52(0.06)$ & $0.44(0.05)$ \\
Broad-sense & 0.91 & 0.94 & 0.93 \\
$\quad$ heritability & & & \\
GCV $(\%)$ & 97 & 63 & 43 \\
PCV $(\%)$ & 110 & 68 & 48 \\
\hline
\end{tabular}

***, $P<0.001 ; \sigma^{2}$, genotypic variance component; $\sigma^{2}{ }_{\text {e }}$, residual variance component.

PCV, Phenotypic coefficient of variation; GCV, Genotypic coefficient of variation. in tillering across these species. Genotypic differences in leaf width are not associated with meristem size per se, as environmental stresses that affect leaf width do not necessarily affect apical dome size at leaf initiation (Mitchell \& Soper, 1958; Beemster \& Masle, 1996). Rather, leaf width is related to the circumference of the subapical meristematic zone of the stem in wheat and Lolium perenne, which is related to the cell number along the intercalary meristem (Mitchell \& Soper, 1958; Beemster \& Masle, 1996). As these cells are generated at the primordial and post-primordial stages (Beemster \& Masle, 1996), this increased cell number would lend support to the view that increased leaf width would increase carbon demand by the main shoot.

The negative relationship between tillering and internode diameter (Tables 7,8 ) is consistent with the carbon S/D framework that large main shoots are associated with low tillering. Similar results were observed by Borrell et al. (2000a,b). Moreover, the main shoot stem diameter of sorghum decreases with increasing plant density (Caravetta et al., 1990), consistent with reduced assimilate availability in response to lower radiation interception per plant. However, the final internode diameter at the base of the stem is only expressed after completion of tillering, making it unlikely that the negative association between internode diameter and tillering is causal. Although it is possible that tillering could drive internode diameter, we hypothesize that the association between the two traits is an emergent consequence of common underpinning processes that determine the expression of both traits, as maximum internode diameter could already be genetically determined in the meristem during tillering. Stem diameter depends on radial growth through lateral meristems (cambium) that are under hormonal control (Ursache et al., 2013). One hormone that promotes cell division in the cambium of dicotyledonous species is strigolactone, which also suppresses tillering (Foo \& Reid, 2013). In such a scenario, the negative genetic correlation between tillering and internode diameter (Table 8) could represent common hormonal control. This would support a close association between the carbon (sugar) and hormonal control of tillering.

Table 7 Phenotypic correlations among the morphological traits of sorghum (Sorghum bicolor) inbred lines (above diagonal) and hybrids (below diagonal) across three different environments

\begin{tabular}{|c|c|c|c|c|c|c|c|c|c|c|c|c|}
\hline Traits $^{\mathrm{a}}$ & TLN & TPH & ID & LA5 & Phyl & LLIR & LWIR & $S / D$ & DTA & N_FT & N_TT & PTT \\
\hline TLN & & $0.26^{\mathrm{ns}}$ & $0.58 * * *$ & $-0.01^{\mathrm{ns}}$ & $-0.61 * * *$ & $-0.01^{\mathrm{ns}}$ & $0.15^{\mathrm{ns}}$ & $-0.15^{\mathrm{ns}}$ & $0.82 * * *$ & $-0.39 * *$ & $-0.31 *$ & $0.11^{\mathrm{ns}}$ \\
\hline TPH & $0.19^{\text {ns }}$ & & $-0.15^{\mathrm{ns}}$ & $0.09^{\mathrm{ns}}$ & $-0.03^{\mathrm{ns}}$ & $0.11^{\mathrm{ns}}$ & $0.19^{\mathrm{ns}}$ & $-0.07^{\mathrm{ns}}$ & $0.31 *$ & $0.00^{\mathrm{ns}}$ & $0.00^{\text {ns }}$ & $-0.02^{\mathrm{ns}}$ \\
\hline ID & $0.86^{* * *}$ & $0.04^{\mathrm{ns}}$ & & $0.31 *$ & $-0.28 *$ & $0.14^{\mathrm{ns}}$ & $0.19^{\mathrm{ns}}$ & $0.00^{\mathrm{ns}}$ & $0.53 * * *$ & $-0.48 * * *$ & $-0.46 * * *$ & $-0.13^{\mathrm{ns}}$ \\
\hline LA5 & $-0.47 * * *$ & $0.27^{\mathrm{ns}}$ & $-0.31 *$ & & $0.04^{\mathrm{ns}}$ & $0.06^{\mathrm{ns}}$ & $0.28 *$ & $0.60 * * *$ & $0.00^{\mathrm{ns}}$ & $-0.15^{\mathrm{ns}}$ & $-0.12^{\mathrm{ns}}$ & $-0.23^{\mathrm{ns}}$ \\
\hline Phyl & $-0.67 * * *$ & $0.02^{\mathrm{ns}}$ & $-0.56 * * *$ & $0.52 * * *$ & & $0.40 * *$ & $0.21^{\mathrm{ns}}$ & $-0.09^{\mathrm{ns}}$ & $-0.21^{\mathrm{ns}}$ & $0.21^{\mathrm{ns}}$ & $0.13^{\text {ns }}$ & $-0.31 *$ \\
\hline LLIR & $-0.66^{* * *}$ & $0.09^{\mathrm{ns}}$ & $-0.68 * * *$ & $0.39 * *$ & $0.68 * * *$ & & $0.25^{\mathrm{ns}}$ & $-0.37 * *$ & $0.20^{\mathrm{ns}}$ & $-0.10^{\mathrm{ns}}$ & $-0.08^{\mathrm{ns}}$ & $-0.24^{\mathrm{ns}}$ \\
\hline LWIR & $0.02^{\mathrm{ns}}$ & $-0.09^{\mathrm{ns}}$ & $0.17^{\mathrm{ns}}$ & $0.41 * *$ & $-0.10^{\mathrm{ns}}$ & $0.00^{\text {ns }}$ & & $-0.42 * *$ & $0.24^{\mathrm{ns}}$ & $-0.53 * * *$ & $-0.58 * * *$ & $-0.44 * * *$ \\
\hline$S / D$ & $-0.02^{\mathrm{ns}}$ & $0.06^{\mathrm{ns}}$ & $0.09^{\text {ns }}$ & $0.47 * * *$ & $0.02^{\mathrm{ns}}$ & $-0.32 *$ & $0.00^{\mathrm{ns}}$ & & $-0.17^{\mathrm{ns}}$ & $0.22^{\mathrm{ns}}$ & $0.27^{\mathrm{ns}}$ & $0.23^{\mathrm{ns}}$ \\
\hline DTA & $0.92 * * *$ & $0.20^{\mathrm{ns}}$ & $0.82 * * *$ & $-0.29 *$ & $-0.54 * * *$ & $-0.63 * * *$ & $0.12^{\mathrm{ns}}$ & $0.13^{\mathrm{ns}}$ & & $-0.37 * *$ & $-0.30 *$ & $0.01^{\mathrm{ns}}$ \\
\hline N_FT & $-0.18^{\mathrm{ns}}$ & $-0.01^{\mathrm{ns}}$ & $-0.32 *$ & $-0.18^{\mathrm{ns}}$ & $-0.10^{\mathrm{ns}}$ & $0.08^{\text {ns }}$ & $-0.43 * *$ & $-0.05^{\mathrm{ns}}$ & $-0.24^{\mathrm{ns}}$ & & $0.96 * * *$ & $0.74 * * *$ \\
\hline N_TT & $-0.30 *$ & $0.16^{\mathrm{ns}}$ & $-0.42 * *$ & $-0.01^{\mathrm{ns}}$ & $0.04^{\mathrm{ns}}$ & $0.19^{\mathrm{ns}}$ & $-0.45^{* *}$ & $-0.03^{\mathrm{ns}}$ & $-0.35^{*}$ & $0.93 * * *$ & & $0.88 * * *$ \\
\hline PTT & 0.07 & $-0.18^{\mathrm{ns}}$ & $0.01^{\mathrm{ns}}$ & $-0.20^{\mathrm{ns}}$ & $-0.44 * * *$ & $-0.26^{\mathrm{ns}}$ & $-0.37 * *$ & $0.28 *$ & $-0.04^{\mathrm{ns}}$ & $0.78 * * *$ & $0.91 * * *$ & \\
\hline
\end{tabular}

${ }^{\mathrm{a}}$ For abbreviations of traits, see Table 2 .

$* * *, P<0.001 ; * *, P<0.01 ; *, P<0.05 ;$ ns, non-significant. 


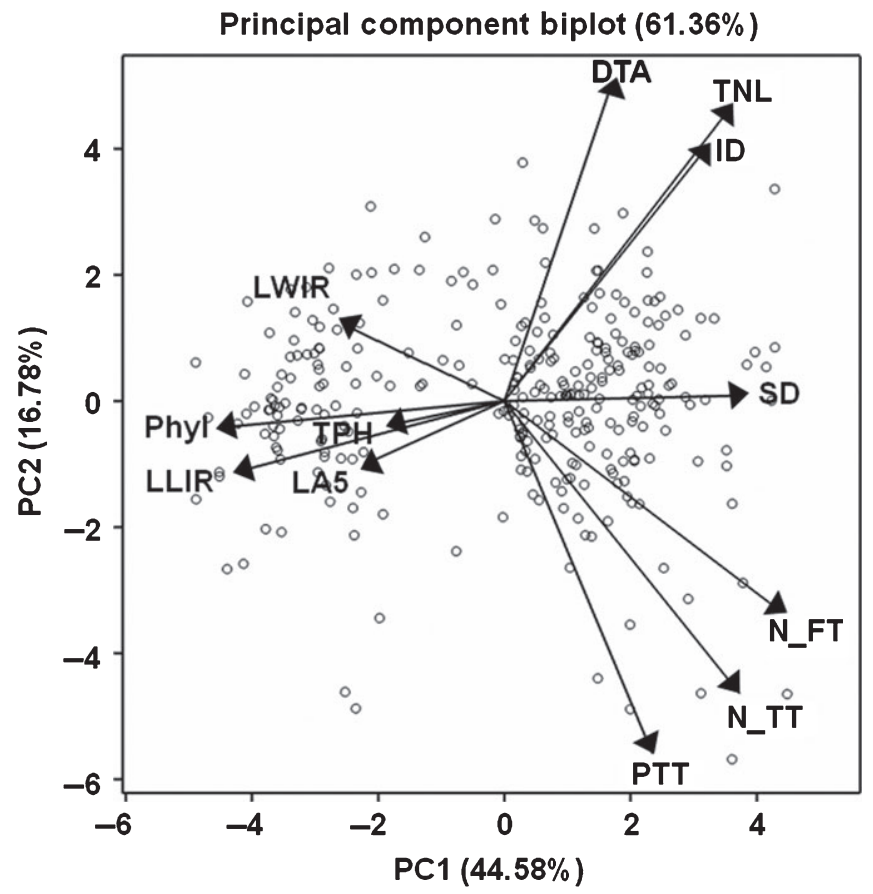

Fig. 2 Principal component (PC) biplot based on the correlation matrix showing genetic correlation among traits of sorghum (Sorghum bicolor) across environments. The biplot was constructed from the predicted genotypic values estimated from best linear unbiased predictors (BLUPS) for 85 genotypes (excluding SC62C and its hybrids and Near Isogenic Lines (NILs) of Expt 2 and Expt 3) by reducing extraneous errors of row, column and replication. DTA, days to anthesis; ID, internode diameter; LA5, area of Leaf number 5; LLIR, leaf length increase rate; LWIR, leaf width increase rate; N_FT, fertile tiller number; N_TT, total tiller number; Phyl, phyllochron; PTT, propensity to tiller; SD, supply/demand index; $\mathrm{TNL}$, total number of leaves; TPH, total plant height.

\section{PTT was a major cause of genotypic differences in tillering}

The PTT explained $>70 \%$ of the genotypic variation in tillering. Genotypes with high PTT have a low threshold S/D index at which tillers start to appear. Such variation in the threshold S/D index supports the involvement of hormonal regulation in the

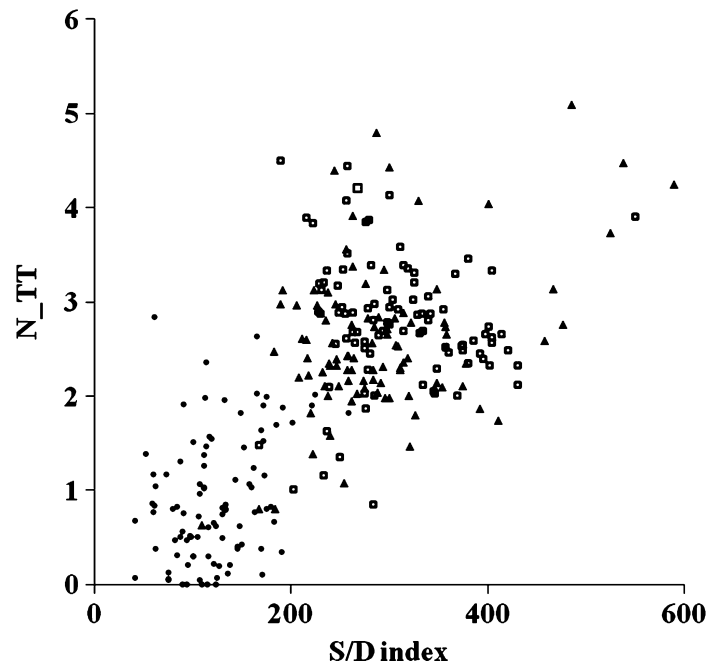

Fig. 3 Total tiller number per plant (N_TT) vs carbon supply/demand index (S/D index) of sorghum (Sorghum bicolor) across three experiments (Expt 1, closed circles; Expt 2, closed triangles; Expt 3, open squares). Trait values of 85 genotypes (excluding SC62C and its hybrids and Near Isogenic Lines (NILs)) were estimated from best linear unbiased estimators (BLUEs). Regression of N_TT on the S/D index in these environments was $y=0.0083 x+0.17, R^{2}=0.56, n=255$.

tillering of sorghum. Auxin, cytokinin and strigolactones can each affect tillering, partly through an effect on apical dominance (Beveridge, 2006; Gomez-Roldan etal., 2008; Ongaro et al., 2008; Umehara et al., 2008; McSteen, 2009). Several genomic regions associated with these hormonal pathways have been identified (Lincoln et al., 1999; Snowden et al., 2005; Xu et al., 2005; Beveridge, 2006; Gomez-Roldan et al., 2008; Ongaro \& Leyser, 2008; Umehara et al., 2008; McSteen, 2009). Hence, genotypic variation in PTT could be regulated by the intrinsic genetic makeup of sorghum plants.

Although the carbon S/D balance and hormonal control represent distinct physiological processes for the control of tillering, these processes can potentially be coordinated. In sorghum, the content of strigolactone 5-deoxystrigol in the roots is enhanced by low nitrogen and phosphorus availability in the soil

Table 8 Genetic correlations among the morphological traits of sorghum (Sorghum bicolor) genotypes (both inbred and hybrids) estimated from three different experiments

\begin{tabular}{|c|c|c|c|c|c|c|c|c|c|c|c|}
\hline Traits $^{\mathrm{a}}$ & $\mathrm{TPH}$ & ID & LA5 & Phyl & LLIR & LWIR & $S / D$ & DTA & N_FT & N_TT & PTT \\
\hline TLN & $0.19^{\text {ns }}$ & $0.59 * * *$ & $-0.23^{*}$ & $-0.48 * * *$ & $-0.22 *$ & $0.00^{\mathrm{ns}}$ & $-0.13^{\mathrm{ns}}$ & $0.82 * * *$ & $-0.40 * * *$ & $-0.35 * * *$ & $-0.26^{*}$ \\
\hline $\mathrm{TPH}$ & & $-0.03^{\mathrm{ns}}$ & $0.14^{\mathrm{ns}}$ & $-0.10^{\mathrm{ns}}$ & $0.10^{\mathrm{ns}}$ & $0.19^{\mathrm{ns}}$ & $-0.10^{\mathrm{ns}}$ & $0.13^{\mathrm{ns}}$ & $0.01^{\mathrm{ns}}$ & $0.02^{\mathrm{ns}}$ & $0.09^{\mathrm{ns}}$ \\
\hline ID & & & $0.16^{\mathrm{ns}}$ & $-0.39 * * *$ & $-0.11^{\mathrm{ns}}$ & $0.25 *$ & $-0.06^{\mathrm{ns}}$ & $0.37 * * *$ & $-0.47 * * *$ & $-0.47 * * *$ & $-0.42 * * *$ \\
\hline LA5 & & & & $0.09^{\text {ns }}$ & $0.12^{\mathrm{ns}}$ & $0.41 * * *$ & $0.52 * * *$ & $-0.20^{\mathrm{ns}}$ & $-0.10^{\mathrm{ns}}$ & $-0.06^{\mathrm{ns}}$ & $-0.22 *$ \\
\hline Phyl & & & & & $0.34 * * *$ & $0.04^{\mathrm{ns}}$ & $0.12^{\mathrm{ns}}$ & $-0.10^{\mathrm{ns}}$ & $0.25^{*}$ & $0.18^{\text {ns }}$ & $-0.01^{\mathrm{ns}}$ \\
\hline LLIR & & & & & & $0.21 *$ & $-0.34 * * *$ & $-0.07^{\mathrm{ns}}$ & $0.01^{\mathrm{ns}}$ & $0.03^{\mathrm{ns}}$ & $0.13^{\mathrm{ns}}$ \\
\hline LWIR & & & & & & & $-0.36^{* * *}$ & $-0.02^{\mathrm{ns}}$ & $-0.45 * * *$ & $-0.51 * * *$ & $-0.41 * * *$ \\
\hline$S / D$ & & & & & & & & $-0.03^{\mathrm{ns}}$ & $0.14^{\mathrm{ns}}$ & $0.19^{\text {ns }}$ & $-0.14^{\mathrm{ns}}$ \\
\hline DTA & & & & & & & & & $-0.37 * * *$ & $-0.32 * * *$ & $-0.31 * *$ \\
\hline N_FT & & & & & & & & & & $0.95 * * *$ & $0.82 * * *$ \\
\hline N_TT & & & & & & & & & & & $0.88 * * *$ \\
\hline
\end{tabular}

${ }^{\mathrm{a}}$ For abbreviations of traits, see Table 2 .

$* * *, P<0.001 ; * *, P<0.01 ; *, P<0.05 ;$ ns, non-significant. 
(Yoneyama et al., 2007). As strigolactones inhibit tillering, it has been speculated that they could provide a signal to communicate the below-ground nutrient status to the growing shoot (McSteen, 2009). However, nutrient deficiency also directly affects the carbon $S / D$ balance through a negative effect on photosynthesis (Muchow \& Sinclair, 1994). Such coordination of the effects of the carbon S/D balance and hormonal pathways on tillering supports the hypothesis that the two pathways are likely to be at least partly under common genetic control.

\section{Model for control of tillering}

The observation that the S/D index accounted for most of the environmental effects on tillering allowed an interpretation of the genetic control of tillering. Our study identified two mechanisms for the control of tillering in sorghum: assimilate availability,

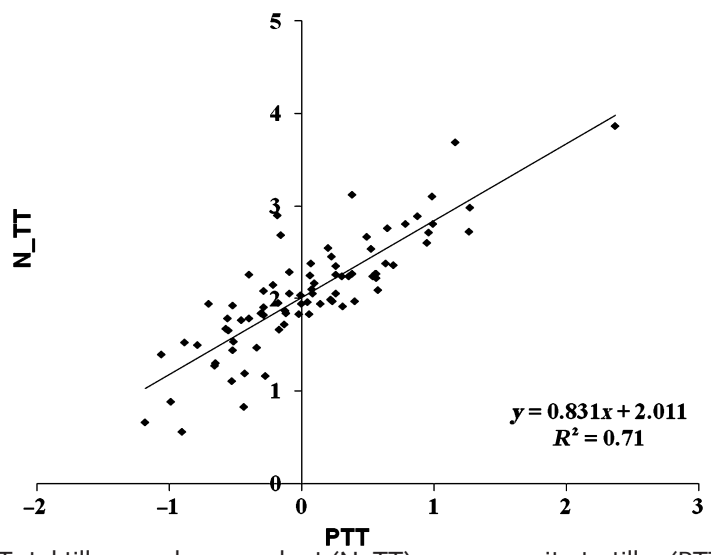

Fig. 4 Total tiller number per plant (N_TT) vs propensity to tiller (PTT) across 85 diverse sorghum (Sorghum bicolor) genotypes. For the calculation of PTT, see the Materials and Methods section.

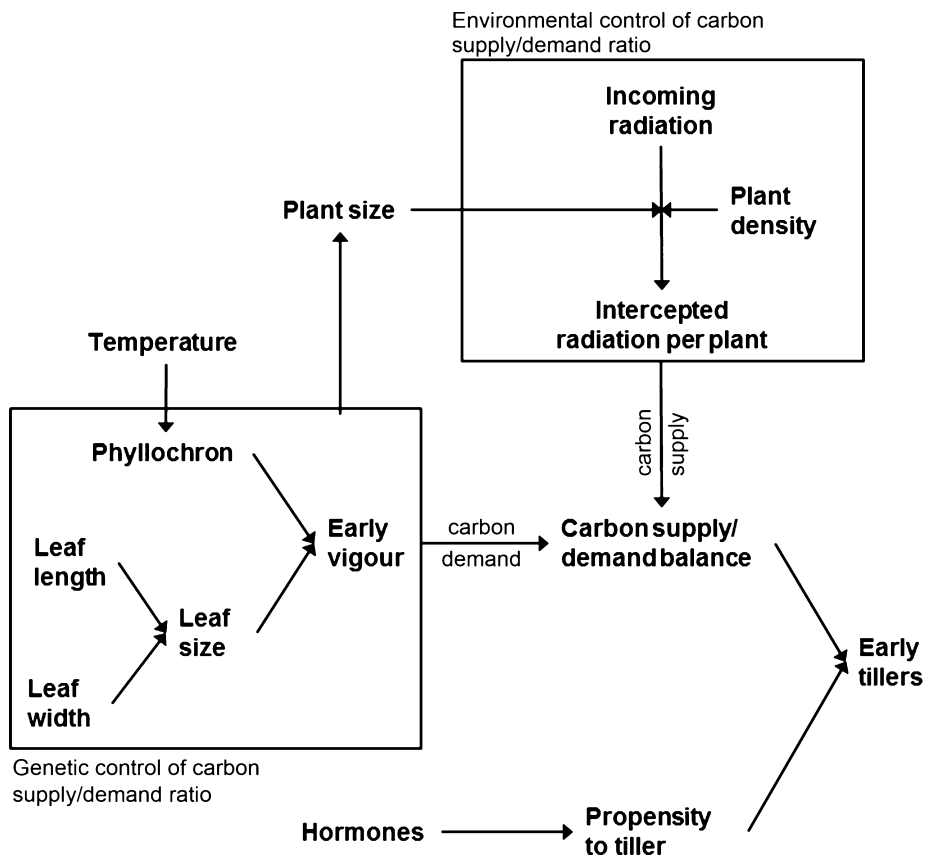

which explained a major part of the environmental control and some of the genetic control of tillering, and PTT, which explained a major part of the genetic variation in tillering. Based on our findings and those reported previously (Lafarge et al., 2002; Kim et al., 2010a,b; van Oosterom etal., 2011), we propose a framework for the physiological control of tillering that captures both genetic and environmental effects on tillering (Fig. 5).

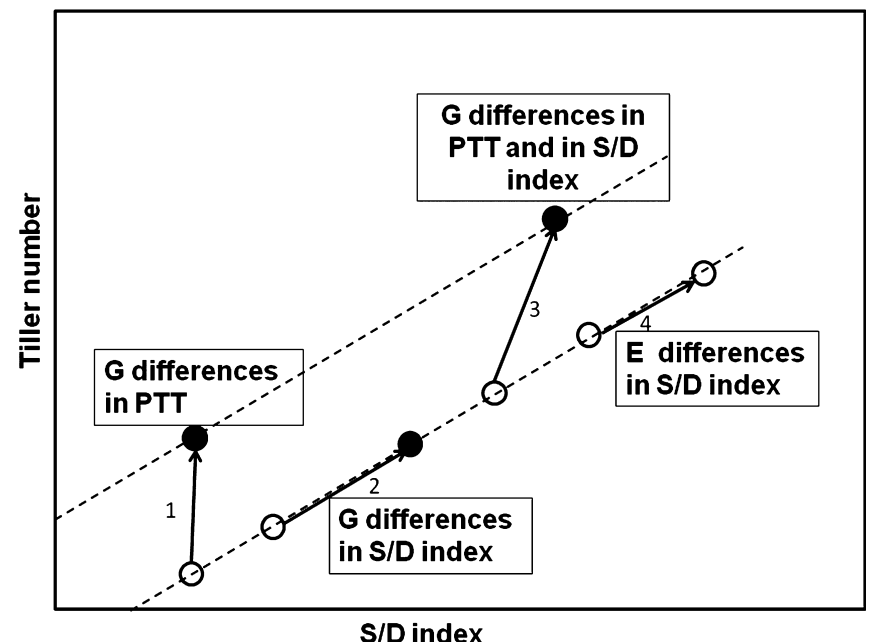

Fig. 6 Schematic representation of the effects of genotypic differences in propensity to tiller (PTT) and supply/demand index (S/D index) and environmental differences in S/D index on the genotype by environment $(G \times E)$ interaction for tiller number in sorghum (Sorghum bicolor). Arrows 1-3 each connect two different genotypes, grown in a single environment. Genotypes differ in PTT (Arrow 1), S/D index (Arrow 2) or both PTT and $S / D$ index (Arrow 3). Arrow 4 connects a single genotype, grown in two experiments, that resulted in a different S/D index. Open symbols, genotypes with low PTT; closed symbols, genotypes with high PTT.

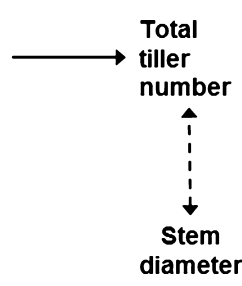

Fig. 5 Physiological framework for the genotypic and environmental regulation of tillering in sorghum (Sorghum bicolor). Double-headed dotted arrow between fertile tiller number and stem diameter represents a non-causal relationship. 
The carbon demand of the main shoots depends on their early vigour. This is determined by the size and appearance rate of leaves, and the rate of development, which depends on temperature. Carbon supply per plant is a function of plant density and radiation intercepted by the crop, which, in turn, depends on the incoming radiation, leaf area, light extinction coefficient (Lafarge \& Hammer, 2002a) and plant density. As carbon availability is most likely to limit tillering during early growth, genotypic and environmental effects on tillering are generally associated with differences in the onset of tillering, and thus with the frequency of appearance of early tillers (Kim et al., 2010a,b). Hence, the carbon S/D framework should capture differences in tiller appearance among pearl millet, sorghum and maize as a consequence of differences in main shoot vigour, which is associated with differences in leaf size. A limitation of the S/D framework, however, is that it only captures the effects of main shoot vigour on the appearance of its subtending primary basal tillers and not of secondary tillers. However, this limitation poses few restrictions in field crops of sorghum, for which the occurrence of secondary tillers is rare. The S/D framework does not capture the cessation of tiller appearance, as this is associated with light quality and, in particular, the ratio of red to far-red light (Casal et al., 1986). The cessation of tiller appearance occurs in sorghum when the leaf area index is c. 0.65 (Lafarge \& Hammer, 2002b). The rate of tiller mortality in sorghum is highly correlated with the ratio of realized to potential leaf area growth, which reflects the carbon S/D balance of the plant (Lafarge \& Hammer, $2002 \mathrm{~b})$. The current $S / D$ framework for tiller appearance could thus be extended to capture tiller mortality. Combined with the PTT, this should provide a comprehensive framework to capture effects of environment, species and genotype on the dynamics of tillering.

The effects of the framework of Fig. 5 on the tillering of diverse genotypes across a range of environments are visualized in Fig. 6, where tiller number and S/D index are linearly related for genotypes with a similar PTT, whereas genotypes with contrasting PTT have a similar slope for this relationship, but vary in the threshold S/D index below which tillering ceases (Kim et al., 2010a). In Fig. 6, Arrows 1-3 each connect two genotypes grown in a single environment. Genotypic variation explained by PTT shifts the relationship between tillering and S/D index vertically (Arrow 1). This would represent the situation with SC62C, which had an extremely high PTT compared with all other genotypes included in this study. Genotypic variation in $\mathrm{S} / \mathrm{D}$ index is captured by moving along a single regression line (Arrow 2), whereas Arrow 3 connects two genotypes that differ in both PTT and S/D index. Arrow 4 connects a single genotype grown across two environments that differ in $S / D$ balance, in a manner similar to Arrow 2. This model captures $\mathrm{G} \times \mathrm{E}$ interactions of a noncrossover type that arise from genotypic differences in the threshold S/D index below which tillering ceases, such as the interaction between R931945-2-2 and Ai4 (Fig. 1), which differed significantly in tillering in Expts 2 and 3, but had each virtually no tillers in Expt 1. The model does not capture the crossover type of $\mathrm{G} \times \mathrm{E}$ interactions, but their importance is relatively minor. This framework provides the basis for the development of a gene-to-phenotype model for tillering that can connect the genetic control of tillering through quantitative trait loci and candidate genes to their phenotypic consequences at the plant or canopy level.

\section{Acknowledgements}

We would like to acknowledge the support of the field staff at Hermitage Research Facility in conducting the experiments. We are also grateful to the Queensland Government and the Grains Research and Development Corporation (GRDC) for providing funding for this research, and to the University of Queensland for providing research scholarships to M.M.A.

\section{References}

Bahmani I, Hazard L, Varlet-Grancher C, Betin M, Lemaire G, Matthew C, Thom ER. 2000. Differences in tillering of long- and short-leaved perennial ryegrass genetic lines under full light and shade treatments. Crop Science 40 : 1095-1102.

Beall FD, Morgan PW, Mander LN, Miller FR, Babb KH. 1991. Genetic regulation of development in Sorghum bicolor. V. The ma3rallele results in gibberellin enrichment. Plant Physiology 95: 116-125.

Beemster GTS, Masle J. 1996. The role of apical development around the time of leaf initiation in determining leaf width at maturity in wheat seedlings (Triticum aestivum L.) with impeded roots. Journal of Experimental Botany 47 : 1679-1688.

Beveridge CA. 2006. Axillary bud outgrowth: sending a message. Current Opinion in Plant Biology 9: 35-40.

Beveridge CA, Weller JL, Singer SR, Hofer JMI. 2003. Axillary meristem development. Budding relationships between networks controlling flowering, branching, and photoperiod responsiveness. Plant Physiology 131: 927-934.

Borràs G, Romagosa I, van Eeuwijk F, Slafer GA. 2009. Genetic variability in duration of pre-heading phases and relationships with leaf appearance and tillering dynamics in a barley population. Field Crops Research 113: 95-104.

Borrell AK, Hammer GL, Douglas ACL. 2000a. Does maintaining green leaf area in sorghum improve yield under drought? I. Leaf growth and senescence. Crop Science 40: 1026-1037.

Borrell AK, Hammer GL, Henzell RG. 2000b. Does maintaining green leaf area in sorghum improve yield under drought? II. Dry matter production and yield. Crop Science 40: 1037-1048.

Bos HJ, Neuteboom JH. 1998. Morphological analysis of leaf and tiller number dynamics of wheat (Triticum aestivum $\mathrm{L}$.): responses to temperature and light intensity. Annals of Botany 81: 131-139.

Caravetta GJ, Cherney JH, Johnson KD. 1990. Within-row spacing influences on diverse sorghum genotypes: I. Morphology. Agronomy Journal 82: 206-210.

Casal JJ, Sanchez RA, Deregibus VA. 1986. The effect of plant density on tillering: the involvement of R/FR ratio and the proportion of radiation intercepted by the plant. Environmental and Experimental Botany 26: 365-371.

Cullis BR, Smith AB, Coombes NE. 2006. On the design of early generation variety trials with correlated data. Journal of Agricultural, Biological and Environmental Statistics 11: 381-393.

Dingkuhn M, Luquet D, Kim HK, Tambour L, Clement-Vidal A. 2006. EcoMeristem, a model of morphogenesis and competition among sinks in rice. 2. Simulating genotype responses to phosphorus deficiency. Functional Plant Biology 33: 325-337.

Doust AN. 2007. Grass architecture: genetic and environmental control of branching. Current Opinion in Plant Biology 10: 21-25.

Dun EA, Ferguson BJ, Beveridge CA. 2006. Apical dominance and shoot branching. Divergent opinions or divergent mechanisms? Plant Physiology 142: 812-819.

Foo E, Reid JB. 2013. Strigolactones: new physiological roles for an ancient signal. Journal of Plant Growth Regulation 32: 429-442. 
Gautier H, Varlet-Grancher C, Hazard L. 1999. Tillering responses to the light environment and to defoliation in populations of perennial ryegrass (Lolium perenne L.) selected for contrasting leaf length. Annals of Botany 83: 423-429. Gilmour AR, Cullis BR, Verbyla AP. 1997. Accounting for natural and extraneous variation in the analysis of field experiments. Journal of Agricultural, Biological and Environmental Statistics 2: 269-273.

Gomez-Roldan V, Fermas S, Brewer PB, Puech-Pages V, Dun EA, Pillot JP, Letisse F, Matusova R, Danoun S, Portais JC et al. 2008. Strigolactone inhibition of shoot branching. Nature 455: 189-194.

Hammer GL. 2006. Pathways to prosperity: breaking the yield barrier in sorghum. Agricultural Science 19: 16-22. (The Journal of the Australian Institute of Agricultural Science and Technology).

Hammer GL, Carberry PS, Muchow RC. 1993. Modeling genotypic and environmental control of leaf area dynamics in grain sorghum. 1. Whole plant level. Field Crops Research 33: 293-310.

Hammer GL, van Oosterom E, McLean G, Chapman SC, Broad I, Harland P, Muchow RC. 2010. Adapting APSIM to model the physiology and genetics of complex adaptive traits in field crops. Journal of Experimental Botany 61: 2185-2202.

Johnson VA, Schmidt JW, Mattern PJ, Haunold A. 1963. Agronomic and quality characteristics of high protein F2-derived families from a soft red winter-hard red winter wheat cross. Crop Science 3: 7-10.

Kariali E, Mohapatra PK. 2007. Hormonal regulation of tiller dynamics in differentially-tillering rice cultivars. Plant Growth Regulation 53: 215-223.

Kim HK, Luquet D, van Oosterom E, Dingkuhn M, Hammer G. 2010a. Regulation of tillering in sorghum: genotypic effects. Annals of Botany 106: 69-78.

Kim HK, van Oosterom E, Dingkuhn M, Luquet D, Hammer G. 2010b. Regulation of tillering in sorghum: environmental effects. Annals of Botany 106: 57-67.

Kirby EJM, Appleyard M, Fellowes G. 1985. Leaf emergence and tillering in barley and wheat. Agronomie 5: 193-200.

Kuraparthy V, Sood S, Gill BS. 2008. Genomic targeting and mapping of tiller inhibition gene (tin3) of wheat using ESTs and synteny with rice. Functional and Integrative Genomics 8: 33-42.

Lafarge M. 2006. Reproductive tillers in cut tall fescue swards: differences according to sward age and fertilizer nitrogen application, and relationships with the local dynamics of the sward. Grass and Forage Science 61: 182-191.

Lafarge T, de Raissac M, Tardieu F. 1998. Elongation rate of sorghum leaves has a common response to meristem temperature in diverse African and European environmental conditions. Field Crops Research 58: 69-79.

Lafarge TA, Broad IJ, Hammer GL. 2002. Tillering in grain sorghum over a wide range of population densities: identification of a common hierarchy for tiller emergence, leaf area development and fertility. Annals of Botany $\mathbf{9 0 :}$ 87-98.

Lafarge TA, Hammer GL. 2002a. Predicting plant leaf area production: shoot assimilate accumulation and partitioning, and leaf area ratio, are stable for a wide range of sorghum population densities. Field Crops Research 77: 137-151.

Lafarge TA, Hammer GL. 2002b. Tillering in grain sorghum over a wide range of population densities: modelling dynamics of tiller fertility. Annals of Botany 90: 99-110.

Li XY, Qian Q, Fu ZM, Wang YH, Xiong GS, Zeng DL, Wang XQ, Liu XF, Teng S, Hiroshi F et al. 2003. Control of tillering in rice. Nature 422: 618-621.

Lincoln C, Britton JH, Estelle M. 1999. Growth and development of the axr1 mutants of Arabidopsis. Plant Cell 2: 1071-1080.

Luquet D, Dingkuhn M, Kim HK, Tambour L, Clement-Vidal A. 2006. EcoMeristem, a model of morphogenesis and competition among sinks in rice. 1. Concept, validation and sensitivity analysis. Functional Plant Biology 33: 309-323.

Mao CZ, Ding WN, Wu YR, Yu J, He XW, Shou HX, Wu P. 2007. Overexpression of a NAC-domain protein promotes shoot branching in rice. New Phytologist 176: 288-298.

McSteen P. 2009. Hormonal regulation of branching in grasses. Plant Physiology 149: 46-55.
Mitchell KJ, Soper K. 1958. Effects of differences in light intensity and temperature on the anatomy and development of leaves of Lolium perenne and Paspalum dilatatum. New Zealand Journal of Agricultural Research 1: 1-16.

Muchow RC, Sinclair TR. 1994. Nitrogen response of leaf photosynthesis and canopy radiation use efficiency in field-grown maize and sorghum. Crop Science 34: 721-727.

Ongaro V, Bainbridge K, Williamson L, Leyser O. 2008. Interactions between axillary branches of Arabidopsis. Molecular Plant 1: 388-400.

Ongaro V, Leyser O. 2008. Hormonal control of shoot branching. Journal of Experimental Botany 59: 67-74.

van Oosterom EJ, Borrell AK, Deifel KS, Hammer GL. 2011. Does increased leaf appearance rate enhance adaptation to postanthesis drought stress in sorghum? Crop Science 51: 2728-2740.

van Oosterom EJ, Carberry PS, O'Leary GJ. 2001. Simulating growth, development, and yield of tillering pearl millet I. Leaf area profiles on main shoots and tillers. Field Crops Research 72: 51-66.

Payne RW, Murray DA, Harding SA, Baird DB, Soutar DM. 2009. GenStat for Windows (13th Edition) introduction. Hemel Hempstead, UK: VSN International.

Rebetzke GJ, Botwright TL, Moore CS, Richards RA, Condon AG. 2004. Genotypic variation in specific leaf area for genetic improvement of early vigour in wheat. Field Crops Research 88: 179-189.

Rebetzke GJ, Richards RA. 1999. Genetic improvement of early vigour in wheat. Australian Journal of Agricultural Research 50(291): 301.

Richards RA. 1988. A tiller inhibitor gene in wheat and its effect on plant-growth. Australian Journal of Agricultural Research 39: 749-757.

Saracutu O, Cnops G, Roldán-Ruiz I, Rohde A. 2010. Phenotypic assessment of variability in tillering and early development in ryegrass (Lolium spp.) In: Huyghe C, ed. Sustainable use of genetic diversity in forage and turf breeding. Berlin, Germany: Springer-Verlag, 155-160.

Schmitz G, Theres K. 2005. Shoot and inflorescence branching. Current Opinion in Plant Biology 8: 506-511.

Shimizu-Sato S, Tanaka M, Mori H. 2009. Auxin-cytokinin interactions in the control of shoot branching. Plant Molecular Biology 69: 429-435.

Snowden KC, Simkin AJ, Janssen BJ, Templeton KR, Loucas HM, Simons JL, Karunairetnam S, Gleave AP, Clark DG, Klee HJ. 2005. The Decreased apical dominance 1/Petunia hybrida CAROTENOID CLEAVAGE DIOXYGENASE8 gene affects branch production and plays a role in leaf senescence, root growth, and flower development. Plant Cell 17: 746-759.

Takeda T, Suwa Y, Kitano H, Ueguchi-Tanaka M, Ashikari M, Matsuoka M, Ueguchi C. 2003. The $O s T B 1$ gene negatively regulates lateral branching in rice. Plant Journal 33: 513-520.

Tardieu F, Granier C, Muller B. 1999. Modelling leaf expansion in a fluctuating environment: are changes in specific leaf area a consequence of changes in expansion rate? New Phytologist 143: 33-43.

Tivet F, Pinheiro BD, De Raissac M, Dingkuhn M. 2001. Leaf blade dimensions of rice (Oryza sativa L. and Oryza glaberrima Steud.). Relationships between tillers and the main stem. Annals of Botany 88: 507-511.

Umehara M, Hanada A, Yoshida S, Akiyama K, Arite T, Takeda-Kamiya N, Magome H, Kamiya Y, Shirasu K, Yoneyama K et al. 2008. Inhibition of shoot branching by new terpenoid plant hormones. Nature 455: 195-200.

Ursache R, Nieminen K, Helariutta Y. 2013. Genetic and hormonal regulation of cambial development. Physiologia Plantarum 147: 36-45.

Whipple CJ, Kebrom TH, Weber AL, Yang F, Hall D, Meeley R, Schmidt R, Doebley J, Brutnell TP, Jackson DP. 2011. grassy tillers 1 promotes apical dominance in maize and responds to shade signals in the grasses. Proceedings of the National Academy of Sciences, USA 108: E506-E512.

Xu M, Zhu L, Shou HX, Wu P. 2005. A PIN1 family gene, OsPIN1, involved in auxin-dependent adventitious root emergence and tillering in rice. Plant and Cell Physiology 46: 1674-1681.

Yaish MWF, Guevara DR, El-Kereamy A, Rothstein SJ. 2010. Axillary shoot branching in plants. In: Pua EC, Davey MR, eds. Plant developmental biologybiotechnological perspectives: volume 1. Berlin, Heidelberg, Germany: Springer-Verlag, 37-52.

Yoneyama K, Xie X, Kusumoto D, Sekimoto H, Sugimoto Y, Takeuchi Y, Yoneyama K. 2007. Nitrogen deficiency as well as phosphorus deficiency in sorghum promotes the production and exudation of 5-deoxystrigol, the host 
recognition signal for arbuscular mycorrhizal fungi and root parasites. Planta 227: $125-132$.

\section{Supporting Information}

Additional supporting information may be found in the online version of this article.

Table S1 Genotypic values for each trait of sorghum inbred lines, estimated from the three experiments using best linear unbiased predictors (BLUPs)
Table S2 Genotypic values for each trait of sorghum hybrids, estimated from the three experiments using best linear unbiased predictors (BLUPs)

Table S3 Genetic correlations for sorghum traits between experiments and broad-sense heritabilities

Please note: Wiley Blackwell are not responsible for the content or functionality of any supporting information supplied by the authors. Any queries (other than missing material) should be directed to the New Phytologist Central Office.

\section{About New Phytologist}

- New Phytologist is an electronic (online-only) journal owned by the New Phytologist Trust, a not-for-profit organization dedicated to the promotion of plant science, facilitating projects from symposia to free access for our Tansley reviews.

- Regular papers, Letters, Research reviews, Rapid reports and both Modelling/Theory and Methods papers are encouraged. We are committed to rapid processing, from online submission through to publication 'as ready' via Early View - our average time to decision is $<25$ days. There are no page or colour charges and a PDF version will be provided for each article.

- The journal is available online at Wiley Online Library. Visit www.newphytologist.com to search the articles and register for table of contents email alerts.

- If you have any questions, do get in touch with Central Office (np-centraloffice@lancaster.ac.uk) or, if it is more convenient, our USA Office (np-usaoffice@ornl.gov)

- For submission instructions, subscription and all the latest information visit www.newphytologist.com 